\title{
Adaptations for Aging at Home in the UK: An Evaluation of Current Practice
}

\section{Wusi Zhou, Adekunle Sabitu Oyegoke \& Ming Sun}

To cite this article: Wusi Zhou, Adekunle Sabitu Oyegoke \& Ming Sun (2019): Adaptations for Aging at Home in the UK: An Evaluation of Current Practice, Journal of Aging \& Social Policy, DOI: 10.1080/08959420.2019.1685347

To link to this article: https://doi.org/10.1080/08959420.2019.1685347

\section{Published online: 30 Oct 2019.}

Submit your article to this journal

山 Article views: 41

Q View related articles ¿

View Crossmark data $₫$ 


\title{
Adaptations for Aging at Home in the UK: An Evaluation of Current Practice
}

\author{
Wusi Zhou, PhD ${ }^{\mathrm{a}}$, Adekunle Sabitu Oyegoke, $\mathrm{PhD}^{\mathrm{b}}$, and Ming Sun, $\mathrm{PhD}^{\mathrm{c}}$ \\ aschool of Public Administration, Hangzhou Normal University, Hangzhou, China; bSchool of Built \\ Environment \& Engineering, Leeds Beckett University, Leeds, UK; 'School of Architecture, Design and \\ the Built Environment, Nottingham Trent University, Nottingham, UK
}

\begin{abstract}
Housing adaptation is necessary to enable elderly people to live independently longer in their own homes. This study aims to review current housing adaptation practice in different parts of the UK and discuss the policy implications at national and local levels. It adopted a mixed-methods research strategy. First, a questionnaire survey was carried out with all 378 local authorities in England, Scotland, and Wales; 112 valid responses were received, representing a response rate of around $30 \%$. Then, interviews and a focus group meeting were conducted with professionals involved in the adaptation process and older clients. The research findings showed that the current number of housing adaptations is relatively small in most local authorities, compared with the potential demand of an aging population. They also revealed some inconsistencies and deficiencies in the system, leading to ineffective and inefficient adaptation service process. These need to be addressed by local authorities in order to improve their adaptation systems and achieve better outcomes.
\end{abstract}

\section{ARTICLE HISTORY}

Received 11 October 2017

Accepted 11 January 2019

\section{KEYWORDS}

Housing adaptation; independent living; care for older people; service process

\section{Introduction}

There is a noticeable correlation between the age of people and long-term illness or disability (Miller, Kirk, Kaiser, \& Glos, 2014). Life limiting illnesses create environmental barriers for older people to live independently, such as stopping them to reach the toilet, have a bath, or go upstairs (Gitlin, 2003; Golant, 2008). However, over $85 \%$ of the older people have a strong desire to remain in their own homes and communities (Farber \& Lynott, 2011). Housing adaptation is recognized as an effective intervention to enhance home accessibility and suitability for independent living (Fänge \& Iwarsson, 2005). The ENABLE-AGE UK project revealed that housing adaptation was a key factor for aging in place and older persons who received adaptations lived longer in their houses than those who did not (Hwang, Cummings, Sixsmith, \& Sixsmith, 2011). Heywood (2004) found that adaptations can benefit both physical and mental health of disabled people. Also, home interventions were reported to prevent falls (Cumming et al., 1999)

CONTACT Wusi Zhou wusi.zhou@hznu.edu.cn $\Theta$ School of Public Administration, Hangzhou Normal University, Hangzhou 311121, China 
and to slowdown the deterioration in quality of life (Bamford, 2000; Watson \& Crowther, 2005). Subsequent research further demonstrated that home modifications can enhance older people's experience of home by restoring home as a place of safety, control, and comfort (Pettersson, Löfqvist, \& Malmgren Fänge, 2012; Tanner, Tilse, \& De Jonge, 2008). Housing adaptations have been defined in different ways (Sanford, 2012). This study adopts the definition of modifications as permanent physical features in the indoor and immediate outdoor in order to reduce environmental barriers and restore independent living (Zhou, Oyegoke, \& Sun, 2019a).

In the UK, local government has the statutory duty to provide grants for housing adaptations, which are assessed as necessary to improve the accessibility of the property and help disabled people remain in their own houses. There are various types of financial assistance, depending on the housing tenure and where a person lives. For example, in England and Wales, although disabled facilities grants (DFGs) are available to people in all housing tenures, local authorities and housing associations normally use their own budgets (e.g., housing revenue account, housing association funding) to undertake adaptations for their tenants. Therefore, DFG is the funding source mainly for private sector adaptations. According to the Local Government and Housing (LCH) Act 1989 and the Housing Grants, Construction and Regeneration (HGCR) Act 1996, a DFG should be awarded when the housing authority is satisfied that an adaptation is necessary and appropriate to meet an applicant's needs and it is reasonable and practicable to adapt the property. To establish whether the adaptation is necessary and appropriate, the housing department should consult the social services department. Since the introduction of home improvement agencies (HIAs) in the Local Government and Housing Act 1989, many local authorities have cooperated with them during the delivery of adaptations. As a result, the adaptation process is administered by different departments and organizations in different local authorities (Heywood, 1994; Zhou et al., 2019a).

Due to imprecise legislation and fragmented responsibilities, the client has to navigate through a number of procedural steps and often a lengthy period elapses before the completion of an adaptation (Mackintosh \& Leather, 2016). In order to streamline the adaptation process and make the best use of scarce resources, national governments commissioned specific groups to review the delivery system for housing adaptations, such as reported by Audit Scotland (2004), Heywood et al. (2005) and Jones (2005). These reviews identified some common deficiencies in existing adaptation practices, including insufficient information on adaptation services, lengthy delays in the delivery of housing adaptation, and inappropriate use of eligibility criteria, and proposed recommendations to address these issues. However, there were certain concerns about whether local governments had followed these recommendations to improve their adaptation services (Adams \& Ellison, 2009). Further, to modernize the adaptation system and to promote a consistent approach for service provision, national guidance on how to organize 
and deliver housing adaptation was published. For example, in 2009, the Scottish Government issued Guidance on the Provision of Equipment and Adaptations to assist local authorities in providing effective adaptation services. This guidance encourages local authorities to place clients at the center of the adaptation process, provide clear service information, and ensure consistency in assessment and service delivery (Scottish Government, 2009). Despite these guidelines, different local authorities still adopted different procedures and practices (Adaptations Working Group, 2012). Therefore, there is a need to investigate the current status of housing adaptation across the UK.

This study is aimed at reviewing and examining the effectiveness of housing adaptation practices in different regions in the UK. It will seek to address three research questions: (i) how do local authorities organize their adaptation services; (ii) what did not work well with the current service delivery system; (iii) to what extent have local authorities implemented national policy objectives for housing adaptations. A mixed-methods research strategy was employed, with a questionnaire survey of all local authorities across England, Scotland, and Wales and interviews and a focus group with key stakeholders.

\section{Policy context of housing adaptations}

\section{The role of local government}

Since responsibilities for housing, health, and social care were transferred to the newly created Scottish Parliament and Welsh Assembly under devolution settlements in 1998, the policy for provision of housing adaptations has been determined and operated by the devolved governments (MacKinnon, 2015). Following decentralization and localism within each nation, intergovernmental relations between central and local governments are closely connected to policies on healthy aging (Greer, 2009). The central government determines the "top-down" policy directions and outcomes, while local authorities adopt the "bottom-up" approach to make decisions on implementing policies and action plans (Trench \& Jeffery, 2007). In this sense, local government plays a central role in setting out proposals for the provision of housing adaptations and deciding the implementation of these proposals. Under the current legislation (e.g., the LGH Act, the HGCR Act), the social services department and the housing department are key partners for the delivery of housing adaptations, with the former providing needs assessments and the latter approving grant applications. This multi-organizational arrangement becomes more complex in some parts of England, where local government operates under a two-tier system, with the county council being responsible for social services while the district council is responsible for housing (Table 1). Therefore, in two-tier areas, the adaptation process spreads across two different levels of authorities. 
Table 1. Levels of government in England.

\begin{tabular}{|c|c|c|c|c|}
\hline Central government & \multicolumn{4}{|c|}{ UK government } \\
\hline Administrative divisions & \multicolumn{2}{|c|}{ Two-tier system } & \multicolumn{2}{|c|}{ Single-tier system } \\
\hline Local governments & County council & District council & Local council & \\
\hline Government Departments & Social services & Housing & Social service & Housing \\
\hline
\end{tabular}

\section{Objectives of housing adaptation policy}

In response to the challenge of demographic change, devolved national governments in the UK have launched their own healthy aging strategies, such as All Our Futures: Planning for a Scotland with an Aging Population 2007 in Scotland, Building a Society for All Ages 2009 in England, and the Strategy for Older People 2013-2023 in Wales. They all set out the overall commitment to making best use of housing and housing-related services in supporting people to remain independent. For example, the 2007 strategy in Scotland highlighted a priority theme of ensuring the right infrastructure for an aging population and defined a set of actions, such as providing older people services and grants to adapt or improve their houses, making age-friendly housing and supporting C\&R services (Scottish Executive, 2007). These initiatives indicate an increased recognition of housing and adaptation services in community care for healthy aging.

The publication of relevant housing strategies further placed the need for housing adaptations within policy actions. In England, the Department for Communities and Local Government (DCLG, 2008) issued the strategy of Lifetime Homes Lifetime Neighborhoods to maximize the impact of the built environment in promoting aging in place. It recognized the contribution of housing adaptations to improved health and independence for older people as well as to substantial savings for the nation. However, the adaptation process was found by a government review as time-consuming and frustrating (Heywood et al., 2005). To speed up the process and meet the rising demand, a strategy was adopted to modernize the DFG system through a list of improvements, such as increasing the budget, raising the upper grant limit, improving the means test, and reducing the bureaucracy. Meanwhile, it highlighted the need to strengthen housing information and advice services, introduce new rapid adaptation schemes, and develop joint work with HIAs for more effective provision. The Scottish government also published its housing strategy of Age, Home and Community and set a policy objective to make best use of existing housing for older people (Scottish Government, 2012). Housing adaptation was recognized as a key contribution to this target. Major changes were needed to improve its delivery and funding arrangements. For example, a single point of contact would enable more people to make requests for housing adaptations and a selfassessment system could be adopted for certain types of adaptations to speed up their delivery. The Welsh government took a unique approach and specified policy objectives for housing adaptation in the above-mentioned aging strategy. 
Its national strategy set a target of making homes and communities suitable for older people to live independently. To achieve this target, the strategy addresses the issue of providing effective adaptation services and establishes a range of monitoring indicators, including the number of DFGs, reduced waiting time, the use of Care and Repair (C\&R) services and Rapid Response Adaptations Programme (Welsh Government, 2013).

To sum up, national strategies in different parts of the UK have recognized the significance of housing adaptations for aging in place and published a range of objectives to streamline the adaptation process for better outcomes. Given the central-local government relation, these strategy aims to represent a framework within which local authorities have the opportunity to develop their own policies and action plans. Therefore, the degree to which the improvement of housing adaptations could be achieved depends on how local authorities design the services and deliver them.

\section{Methodology}

\section{Sample}

This study adopts an evaluation approach to assess the effectiveness of current housing adaptation practice, which is principally shaped by national and local strategies and policies in the UK. It chooses to focus on homeowners and private tenants instead of local authorities or housing association tenants. The reason for this choice is twofold. Firstly, owner occupiers and private tenants account for the majority of households in the UK; they are the main users of adaptation services. Secondly, most of them have little knowledge about where to start and what assistances are available when they need adaptations. The study excluded Northern Ireland, as it has a unique Health and Social Services, which is different from other nations in the UK (Boniface, Mason, Macintyre, Synan, \& Riley, 2013). There are in total 414 local authorities across England, Scotland, and Wales. Of those, 36 local authorities were excluded as they did not provide adaptation services directly. A questionnaire survey was carried out with all the remaining 378 local authorities. After the survey, a sample of stakeholders, including service providers and service users, were approached for interviews and a focus group meeting.

\section{Data collection}

The questionnaire survey was designed to investigate how local authorities plan, organize, and monitor their adaptation services. It contains 36 questions in 6 sections covering planning, partnership, referral, assessment, installation, and monitoring. Prior to the main survey, a pilot study was carried out with 12 local councils. As a result of the pilot, modifications were made to some questions. The 
finalized questionnaire was posted to the housing departments of all local councils, along with a cover letter and postage prepaid envelope. The questionnaire was also made available online for those who preferred to reply online. Reminder phone calls were made to non-respondents after 4 weeks, followed by e-mail reminders. In the end, a total of 112 local authorities responded to the survey, with 61 completed and returned by stamped envelopes, 28 completed online, and another 23 submitted by e-mail. The response rate was $29.6 \%$, which is comparable to other studies, such as Davies et al. (2012) and Westlin and Björklund (2016). More importantly, the results of this study are broadly in line with findings from other survey studies reviewing housing adaptations in the UK, such as Bibbings et al. (2015), Jones (2005) and Heywood et al. (2005), which were commissioned by central governments toward their local authorities. A post-survey analysis showed that those who did not reply shared the characteristics of operating tenure-based funding systems and separating the process into different stages that involved different organizations.

For a deeper understanding of issues identified by the quantitative results, qualitative data were collected through interviews and a focus group. The interviews were conducted with different stakeholders, including five professionals and two older clients. These professionals worked in different departments or organizations responsible for different stages of the adaptation process; they were interviewed for 60 to $150 \mathrm{~min}$ in their offices. Clients, who were aged 65 or older with disabilities and had received an adaptation in the last 2 years, were interviewed in their own houses for around $60 \mathrm{~min}$. These interviews obtained information of different perspectives of the process of adaptations and key blockages within the current process. A focus group meeting was organized in one local council where the social work, the housing department, and C\&R typically worked in partnership for the provision of housing adaptation. The focus group participants, including one OT, two housing officers, one technical officer, one C\&R manager, and one coordinator, have worked as a team to provide adaptation services for more than 2 years. The focus group discussion gained a more comprehensive picture of the delivery system for housing adaptation and its existing problems. All interviews and focus group discussions were recorded and transcribed verbatim afterward.

\section{Statistical analysis}

Survey data were analyzed using the statistical package for the social science. Descriptive statistics were applied to identify organizational features of housing adaptations. Frequency tables displayed local authorities' responses to separate variables in each question, which summarized similarities and differences between local adaptation practices from referral to installation. Bivariate and multivariate analysis was employed to examine 
relationships between variables and to determine key factors that impacted the effectiveness of the adaptation process. Qualitative data from the interviews and focus group were analyzed using NVivo and coded thematically to add greater depth to analysis of key issues within current adaptation provision.

\section{Results}

The adaptation process consists of several steps, including referral, case allocation, need assessment, funding decision, and installation. It usually starts when a referral for an adaptation is made to the welfare authority (e.g., social services in England and Wales, social work in Scotland) through GP, social worker, or other professionals. Sometimes clients can fill out a form to refer themselves. On receipt of referrals, an initial screening normally takes place to prioritize the cases and allocate them to specific fieldworkers, mainly occupational therapists (OTs), for assessments. After allocation, the fieldworkers make home visits to assess the needs against local eligibility criteria and decide the types of adaptations required. The case is then passed to the housing officer for grant approval. If the client is a tenant, it is necessary to obtain landlord permission before undertaking any adaptation. Once the grant is approved and the specification of the adaptation work is confirmed, contractors are invited to submit quotes for its installation. A contractor will be selected by the client to carry on the work and will invoice the local authority after completion.

\section{Referral to allocation}

Table 2 presents survey results associated with the adaptation process from referral to installation. Adaptation request can be triggered through referral by a healthcare professional or self-referral by an applicant. In fact, the self-referral system allows applicants to quickly initiate the adaptation process and helps local authorities to reduce the associated administration costs, as confirmed by a social worker:

Most people waiting for adaptations are first asked to self-referral through an online system. This saves our staff lots of time and helps people to enter the service quickly.

However, $46.5 \%$ of the local authorities did not receive any referrals made directly by applicants; another $29.3 \%$ received no more than $25 \%$ self-referrals. There was relatively poor awareness of adaptation services among private occupants/tenants, with $54.3 \%$ of the respondents considering the service awareness as poor or fair. Because of political pressure to meet the increasing demand, many local authorities did not advertise the availability of adaptation grants or provide detailed service information, as reported by a housing officer: 
Table 2. Descriptive statistics of variables related to delivery process.

\begin{tabular}{|c|c|c|}
\hline Referral & Yes $(n)$ & (\%) \\
\hline A standard form/a shared IT system to collect basic information & 66 & 61.1 \\
\hline \multicolumn{3}{|l|}{ Self-referrals } \\
\hline None & 46 & 46.5 \\
\hline $1 \%-25 \%$ & 29 & 29.3 \\
\hline $26 \%-50 \%$ & 5 & 5.1 \\
\hline $51 \%-75 \%$ & 10 & 10.1 \\
\hline Over $75 \%$ & 9 & 9.1 \\
\hline \multicolumn{3}{|l|}{ Awareness of adaptation services } \\
\hline Poor & 19 & 18.1 \\
\hline Fair & 38 & 36.2 \\
\hline Good & 43 & 41.0 \\
\hline Excellent & 5 & 4.8 \\
\hline Allocate the applicant a key caseworker & 103 & 97.2 \\
\hline Initial screening mechanisms to prioritise referrals & 79 & 77.5 \\
\hline Set target waiting time for assessment of different priority cases & 23 & 24.0 \\
\hline \multicolumn{3}{|l|}{ Assessment } \\
\hline \multicolumn{3}{|l|}{ Other assessment arrangements except OT (multiple responses) } \\
\hline None & 42 & 40.0 \\
\hline Self-assessment & 21 & 20.0 \\
\hline OT assistant assessment & 51 & 48.6 \\
\hline Other (e.g. social worker, technical officer, HIA or C\&R) & 19 & 18.1 \\
\hline \multicolumn{3}{|l|}{ Determinants for OT assessment (multiple responses) } \\
\hline Needs of the applicant & 50 & 79.4 \\
\hline Complexity of the case & 37 & 58.7 \\
\hline Cost of the adaptation & 7 & 11.1 \\
\hline Other (e.g. necessary and appropriate, client state, delays) & 9 & 14.3 \\
\hline Keep the applicant inform of assessment progress & 81 & 89.0 \\
\hline Apply national criteria to determine eligibility for adaptations & 40 & 46.0 \\
\hline \multicolumn{3}{|l|}{ Factors in the local eligibility framework (multiple responses) } \\
\hline Health condition & 52 & 89.7 \\
\hline Living environment & 43 & 74.1 \\
\hline Community participation & 31 & 53.4 \\
\hline Care arrangement & 41 & 70.7 \\
\hline Other (e.g. discharge from hospital, age, dependence) & 15 & 25.9 \\
\hline \multicolumn{3}{|l|}{ Principle for deciding priority for funding } \\
\hline Any of the factors is high priority & 7 & 10.4 \\
\hline All or majority of the factors are high priority & 2 & 3.0 \\
\hline A balanced judgement of priority of factors & 34 & 50.7 \\
\hline Other (e.g. priority score, rank, points) & 24 & 35.8 \\
\hline \multicolumn{3}{|l|}{ Effectiveness of assessments } \\
\hline Very ineffective & 3 & 3.8 \\
\hline Fairly ineffective & 4 & 5.1 \\
\hline Fairly effective & 40 & 51.3 \\
\hline Very effective & 31 & 39.7 \\
\hline \multicolumn{3}{|l|}{ Installation } \\
\hline Keep a list of contractors to help applicants & 78 & 70.9 \\
\hline \multicolumn{3}{|l|}{ Ways to advertise the list (multiple responses) } \\
\hline On request & 46 & 59.0 \\
\hline On website & 9 & 11.5 \\
\hline In information package & 29 & 37.2 \\
\hline Other (e.g. agency service, in-house surveyor) & 21 & 26.9 \\
\hline Help the applicant to understand the specification of adaptation & 106 & 96.4 \\
\hline \multicolumn{3}{|l|}{ A procedure to review approved grant (multiple responses) } \\
\hline Yes, inform to spend within the financial year & 14 & 13.1 \\
\hline Yes, inform a deadline to spend & 46 & 43.0 \\
\hline No, all depend on the applicant & 38 & 35.5 \\
\hline Other (e.g. allow flexibility, overseen by agencies or staff) & 33 & 30.8 \\
\hline
\end{tabular}


If we advertise the service, we have to deal with the increased work. People have to wait longer, because there are no extra expenses.

Although there were a range of referral routes, $38.9 \%$ of the local authorities did not have a standard inquiry form or a shared IT system covering all access points to collect basic information needed for assessment, as highlighted by a social worker:

We often get poor information. A worst-case scenario is, a GP sees an older person and would say, Ms. X is really struggling and needs an OT assessment. But we don't know how urgent the case is and we don't know in which way the person is struggling with, so she is put in the waiting list.

After receiving initial inquiries, $97.2 \%$ of the local authorities informed every applicant of a key caseworker who has oversight of their application; $77.5 \%$ of the local authorities used a screening mechanism to prioritize referrals for assessments. When a priority framework is used, referrals often fall into three bands of high, medium, or low priority (Home Adaptations Consortium [HAC], 2013). It was found that local authorities managed to carry out quicker assessment visits for high priority cases than for medium or low priority ones. The social worker continued to comment:

After screening, each referral has its own priority, which will then decide which type of assessment the client needs and how fast they must be seen.

An OT further added that the initial screening allowed them to focus on more complex requests:

A priority scoring system gives us the opportunity to deal with the most complicated situations and to visit high priority cases more quickly.

Despite this, only 23 local councils have set explicit target waiting times for assessment of different priority categories. On average, the target waiting time for high priority cases was 7 days, compared with 28 days for medium and 71 days for low priority cases. Moreover, $94 \%$ of the high priority cases have been assessed by OTs within the target timescale, while the completion rate for medium and low priority cases decreased to $64 \%$ and $62 \%$, respectively. A C\&R officer reported:

The high priority cases will be dealt with first; those with low points could wait for years to get their adaptations.

\section{Assessment to funding}

Before considering eligibility, an assessment must be carried out to establish the extent of needs. Traditionally, OTs have been employed to carry out adaptation assessments, but their professional practice was not founded on a regulatory and guidance framework (Heywood, 1994). There have been inconsistencies in the use 
of OTs; $40.0 \%$ of the local authorities always required them to do assessments, while the rest only involved them in complicated cases and appointed ancillaries, such as OT assistants and social workers, to deal with the simple requests. Meanwhile, 21 local councils have adopted self-assessment models for lowerlevel adaptations. These ancillary assessments have positively impacted the effectiveness of local assessment systems, as evidenced by previous research, such as Adams and Ellison (2009) and Jones (2005), as well as this study. The survey found that local authorities, who only relied on OT assessments, had a less effective assessment process than those using diverse types of assessment (Table 3). This was also confirmed by a social worker:

The use of OT assistants for less complex case is effective to alleviate delays in getting assessment.

Given the use of multiple assessment arrangements, many local authorities have set down criteria for deciding whether an OT assessment is required for each case. However, the criteria varied from one council to another. $79.4 \%$ of the local authorities included the criterion of the applicant's needs; 58.7\% relied on the case's complexity and $25.4 \%$ considered other factors, such as cost of the adaptation and delays in obtaining assessments.

Eligibility threshold enables local authorities to deploy limited resources for those most in need and to distribute adaptation funds in a fair manner (Lett, Sackley, \& Littlechild, 2006). National standard eligibility criteria were published to promote consistent and equitable provision of housing adaptations across all local areas (Scottish Government, 2009). However, 46.0\% of the local authorities have not applied national criteria to determine eligibility for the provision of housing adaptations. As a result, there have been considerable variations in local eligibility criteria. A policy officer pointed out:

Each local authority operates their own eligibility criteria and as there are XX local authorities, huge variations exist in their criteria for the provision of adaptations.

Health condition was the most important factor; $89.7 \%$ of the local authorities have set different health eligibility criteria, such as terminal illness, inability to manage nutrition, inability to maintain personal hygiene, inability to get dressed independently, and inability to manage toilet needs. Next came factors related to living environment (74.1\%) and care arrangement (70.7\%). For living environment, local authorities considered whether the client was

Table 3. Crosstabs between only OT assessment and effectiveness of assessment arrangements.

\begin{tabular}{lcccc}
\hline & \multicolumn{4}{c}{ Effectiveness of current assessment arrangements } \\
\cline { 2 - 5 } Only OT assessment & Very ineffective & Fairly ineffective & Fairly effective & Very effective \\
\hline Yes & 3 & 3 & 14 & 8 \\
& $100.0 \%$ & $75.0 \%$ & $35.0 \%$ & $25.8 \%$ \\
No & 0 & 1 & 26 & 23 \\
& $0.0 \%$ & $25.0 \%$ & $65.0 \%$ & $74.2 \%$ \\
\hline
\end{tabular}


capable of carrying out domestic routines, controlling vital aspects of living environment, and/or maintaining a habitable home environment. As for care arrangement, local authorities took account of absence of carer, care relationship, and the carer's ability. Among local authorities, 53.4\% also assessed the impact of community participation, such as the ability to participate in work, to undertake social roles, or to use public services and facilities.

As a range of factors were described in the local eligibility framework, there was inevitably a judgment of applying these factors in each case. Of local authorities, $50.7 \%$ determined the priority of an application for funding based on a balanced judgment of all eligibility factors. In contrast, another $10.4 \%$ used more loose criteria, making decisions on eligibility when any of the risk factors was rated as high priority. Due to complexity in assessment arrangements and eligibility criteria, it is easy for applicants to get lost in the assessment process (HAC, 2013). To prevent it, $89.0 \%$ of the local councils regularly kept the applicant informed on progress with their assessment, as reported by an older client:

I don't need to get in touch with local authority, they will let me know what happens next and when the OT will visit.

Although $91.0 \%$ of the respondents felt that their assessment system worked well, rated as either fairly effective or very effective, there were still complaints of delays in the assessment process:

We often experience delays and waiting lists for OT assessments, which can cause bottlenecks in the process. (a housing officer)

\section{Installation}

Once a grant has been authorized, the process of installation can go ahead. Firstly, the client's needs must be translated into the specification of an adaptation. This specification needs to be agreed between professionals and clients as it is linked to the desired outcome; 106 local councils helped clients to understand their adaptation specification. When the detailed specification is finalized, the client starts to seek quotations but frequently faces difficulties in finding skilled contractors (Bibbings et al., 2015). To help clients, 78 local councils maintained a list of contractors; $59.0 \%$ of the councils provided approved contractors when the client requested, $37.2 \%$ of the councils included the list in the service package, and $11.5 \%$ provided such information on their websites. Those councils that have not yet compiled this list expected to have more suitable contractors in place to minimize the waiting time for installation, as put forward by a housing officer: 
The DFG process is very prescriptive. It could be speeded up, if this was altered, or if we had the funding to recruit more staff, or if there were more contractors with relevant experience in this area.

As the timing of the installation work is decided by clients, there is a risk of the process being put on hold due to indecision by the client. A social worker pointed out:

"You will be surprised by a number of people who just take for ever to get the ramp or shower done. You would think that they will do it straight away, but they don't.

According to the HGCR Act, the adaptation work should be carried out within 12 months after the approval of grants, but local authorities can extend this period when there are reasonable causes. The survey found that $35.5 \%$ of the local authorities allowed approved grants to be carried forward to the next year if not spent within this financial year, while $56.1 \%$ councils set a deadline of either a period of time or the financial year within which the grant should be spent, otherwise it would be withdrawn. Some councils allowed an extension of the deadline when causes were reasonable. A housing officer explained:

We will inform the applicant to spend the grant within the financial year, otherwise the grant may be withdrawn. Depending on the circumstances we will carry the grant forward to the next financial year.

Table 4 shows average numbers of adaptations and amounts of funding at the local authority level across the UK. The average number of adaptations completed in 2014/15 was 154 per local authority. However, $71.6 \%$ of the local authorities carried out fewer than the average number, with 49 authorities completing no more than 100 adaptations. Similarly, the average spending for adaptations was $£ 777,081$ per local authority and $70.6 \%$ of the local authorities spent less than this average amount. Clearly, the supply of housing adaptations was far behind the increasing demand, as complained by a housing officer:

More and more older people demand adaptations, which always outstrips supply in our council.

\section{Discussion}

Dissatisfaction with the current adaptation process centered on its complexity, prolixity, and variety. The process often includes five key stages with different organizations assuming responsibility for different stages. At the referral and allocation stages, some local authorities did not operate a standard approach toward inquiries from different routes, which could adversely affect service 


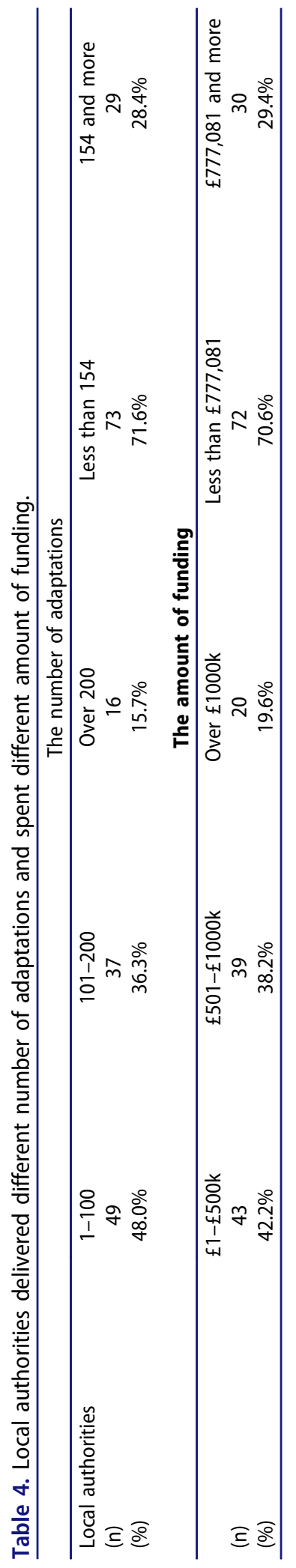


quality. For service users, initial requests for adaptations may take longer to reach OTs or even be put aside in the event that information on applicants is incomplete. For service providers, it is virtually impossible to provide effective and consistent responses to all referrals. Therefore, there is a need for a standard approach or a single access point to process all enquires equally and efficiently within the local authority. Although self-referrals can help local authorities to speed up the referral process and get maximum benefits from their adaptation budgets, there were no or only few referrals made by applicants themselves in most local authorities. Unsurprisingly, public awareness of adaptation services remained quite low in most local authorities. To address this, it is important that local authorities take measures, such as leaflets, meetings, agencies, and the internet (HAC, 2013), to raise awareness for people in need of the adaptation service. Due to the complexity of the adaptation process, it is not always easy for clients to find out which stage they are in. To help the client, most local authorities allocated a key caseworker who could be contacted for any information throughout the whole process. The initial screening mechanism was widely deployed; it helped local authorities to provide effective responses to urgent needs. However, non-urgent applicants probably wait longer. To prevent this, it is essential for local authorities to set a target response time for assessment of all priority categories.

At the assessment and funding stages, lengthy waiting time was common as OTs were always overwhelmed by the volume of requests (Zhou, Oyegoke, \& Sun, 2019b). In order to back up the OT's services and speed up the assessment process, most local authorities have deployed OT assistants, other assessors, and self-assessments for less complicated cases. These ancillary assessments offered a good solution to the long waiting list for OT assessments. Indeed, working collaboratively is key to streamlining the assessment process and delivering a seamless service. As evidenced by the CAPABLE program in Szanton et al. (2014), an interdisciplinary team of a nurse, OT, and handyman could work effectively to improve the home environment and the participant's function. However, there were certain concerns that OT assistants might lack the skills or experiences required to pick up hidden needs and make expert diagnoses (Bibbings et al., 2015). Therefore, additional trainings are necessary to ensure that appointed ancillaries have the right knowledge and are competent to carry out assessments for minor works. Local authorities have established different criteria to determine whether an OT would be called in to give assessment. This indicates that the threshold for OT assessment can be easily shifted by local policies. There is a danger that cases that need the professional input of OTs are allocated to OT assistants. To minimize this danger, local authorities should ensure that the decision for OT assessment is made by professionally qualified staff. Although a national eligibility framework was issued by central governments, criteria for accessing housing adaptations varied markedly across the country. Risks related to health, living environment, and care arrangement have 
been widely accepted as eligibility criteria, but they were defined differently in different local authorities. Some local councils set relatively rigid criteria for adaptation funding, while others had a loose set. This means that what was eligible for a DFG in one place might be not eligible elsewhere and there was potential inequality or "postcode lottery" in the provision of adaptations. To prevent it, central government should introduce a minimum eligibility threshold for providing adaptations, while local government set their own eligibility criteria in accordance with national standards.

At the installation stage, the final specification of an adaptation was normally confirmed with the client in most local authorities. This is essential for clients to understand what is going to be done in their houses and for the installation process to go ahead quickly. Local authorities tended to keep a list of trusted contractors, but this list was not widely advertised. As a result, clients may have to spend more time in obtaining tenders from contractors. Therefore, it is important for local authorities to establish an approved list of contractors and give it wide publicity. As clients have the final say on when adaptation work can start, it was found that delays were sometimes caused by them. There were two opposite ways to deal with grants that are not spent within the given time, withdrawal or allowing to be carried forward. This divergence reflected inconsistent practices among local authorities, which resulted in inequality of access to adaptation service provision. To address it, further legislation and guidance is needed to give a clear explanation of when the installation should be started and under which circumstances the timescale can be extended. Overall, there were remarkable differences in the number of adaptations and the levels of spending between local authorities. Most local authorities carried out a relatively small number of adaptations each year, compared with potential needs from population aging. The level of government spending was also low, meaning that the current funding allocation was not sufficient to meet the existing demand in many local areas. There should be a substantial increase in resources so that adaptation services can support more older people aging in their own houses.

\section{Limitations}

While this study brought new understanding of the current delivery systems for housing adaptations in the UK, there are some limitations. First, recruiting local authorities to the survey and getting a high response rate proved to be a challenge. Such a difficulty, especially for independent research, was recognized by others (Siegel \& Ellis, 1985). Local officers responsible for housing adaptations are often overwhelmed by caseloads; helping with research is not their priority. This helps to explain the relatively low response rate for our survey. Therefore, caution should be used when generalizing the research findings. Another difficulty was caused by variations in local adaptation practices related to resources, teams, and procedures. Due to these differences, not all questions are applicable to all local 
authorities. Finally, the definition of performance effectiveness might not be shared by other practitioners. Further research is needed on standardizing the adaptation process across local authorities so that performance can be easily measured and best practices identified.

\section{Conclusion}

Housing adaptation helps older people stay in their homes longer and has been given great political priority in many countries. In the UK, the national government sets adaptation strategy and policies while local authorities are responsible for policy implementation. The survey results of this study revealed some good practices, such as the key caseworker, regular progress reports, and agreement on the specification. However, the current implementation of adaptation policies is limited in most local areas. There is a relatively small number of adaptations with low levels of spending, compared with the potential needs of an aging population. Extra sources of funding need to be tapped at both national and local levels, so that adaptation services can reach more people in need across all local authority areas.

Housing adaptation practice varies significantly across the whole country. Some common deficiencies have caused inefficiencies and ineffectiveness of the service, presenting important implications for policies related to healthy aging and community care. First, there are many inconsistencies and inequities in the adaptation process between local authorities, including initial referral, assessment arrangements, and eligibility criteria. To ensure equal access to adaptation services across the whole country, it is important to introduce a unified national approach for housing adaptations with a minimum eligibility threshold applied in all local areas. At present, various priority systems are used, which lead to faster processing of urgent cases but uncertainty for non-urgent applicants. Therefore, a reasonable maximum waiting time should be set for all cases, including medium or low priority cases. Furthermore, delays are often found during adaptation process. A range of positive actions, such as using multiple assessment arrangements and establishing a list of contractors, can be taken to minimize the waiting time and achieve a seamless service process.

\section{Acknowledgments}

The authors would like to thank Care and Repair Scotland, local authorities across England, Scotland and Wales, and other research participants who shared their time and experiences.

\section{Disclosure statement}

No potential conflict of interest was reported by the authors. 


\section{Funding}

This research received no external funding.

\section{References}

Adams, S., \& Ellison, M. (2009). Home adaptations for older people: The increase in need and future of state provision. Nottingham, UK: Care \& Repair England.

Adaptation Working Group. (2012). Adapting for change. Edinburgh: Scottish Government.

Bamford, C. (2000). Surveying outcomes of equipment and adaptations. York, UK: Social Policy Research Unit, University of York.

Bibbings, J., Boniface, G., Campbell, J., Findlay, G., Reeves-McAll, E., Zhang, M., \& Zhou, P. (2015). A review of independent living adaptations. Cardiff, UK: Welsh Government.

Boniface, G., Mason, M., Macintyre, J., Synan, C., \& Riley, J. (2013). The effectiveness of local authority social services' occupational therapy for older people in Great Britain: A critical literature review. British Journal of Occupational Therapy, 76(12), 538-547. doi:10.4276/ $030802213 X 13861576675240$

Cumming, R. G., Thomas, M., Szonyi, G., Salkeld, G., O’Neill, E., Westbury, C., \& Frampton, G. (1999). Home visits by an occupational therapist for assessment and modification of environmental hazards: A randomized trial of falls prevention. Journal of the American Geriatrics Society, 47(12), 1397-1402. doi:10.1111/jgs.1999.47.issue-12

Davies, K., Bullock, M., Brandon, A., Wainman, K., Craig, L., Fletcher, P., \& Duncan, A. (2012). A study of the housing and support needs of older people in Herefordshire. Northumberland, UK: Peter Fletcher Associates Ltd.

Department for Communities and Local Government. (2008). Lifetime homes, lifetime neighbourhoods. London, UK: DCLG Publications.

Department for Communities and Local Government. (2009). Survey of English Housing, 2007-2008. London, UK: DCLG Publications.

Fänge, A., \& Iwarsson, S. (2005). Changes in ADL dependence and aspects of usability following housing adaptation-A longitudinal perspective. American Journal of Occupational Therapy, 59(3), 296-304. doi:10.5014/ajot.59.3.296

Farber, N., \& Lynott, J. (2011). Aging in place: A state survey of livability policies and practices. Washington, US: AARP Public Policy Institute.

Gitlin, L. N. (2003). Conducting research on home environments: Lessons learned and new directions. The Gerontologist, 43(5), 628-637. doi:10.1093/geront/43.5.628

Golant, S. M. (2008). Commentary: Irrational exuberance for the aging in place of vulnerable low-income older homeowners. Journal of Aging \& Social Policy, 20(4), 379-397. doi:10.1080/08959420802131437

Greer, S. L. (2009). Devolution and health policy in the UK. Eurohealth, 14(4), 22.

Heywood, F. (1994). Adaptions: Finding Ways to Say Yes. Bristol, UK: School of Urban Studies.

Heywood, F. (2004). The health outcomes of housing adaptations. Disability \& Society, 19(2), 129-143. doi:10.1080/0968759042000181767

Heywood, F., Gangoli, G., Langan, J., Marsh, A., Moyers, S., Smith, R., ... Hamilton, J. (2005). Reviewing the disabled facilities grant programme. London, UKf: Office of the Deputy Prime Minister.

Hwang, E., Cummings, L., Sixsmith, A., \& Sixsmith, J. (2011). Impacts of home modifications on aging-in-place. Journal of Housing for the Elderly, 25(3), 246-257. doi:10.1080/ 02763893.2011.595611 
Jones, C. (2005). Review of housing adaptations including disabled facilities grants - Wales. Cardiff, UK: Welsh Government.

Lett, K., Sackley, C., \& Littlechild, R. (2006). The use of fair access to care services' eligibility criteria for equipment provision within local authorities in England. The British Journal of Occupational Therapy, 69(9), 420-422. doi:10.1177/030802260606900905

MacKinnon, D. (2015). Devolution, state restructuring and policy divergence in the UK. The Geographical Journal, 181(1), 47-56. doi:10.1111/geoj.2015.181.issue-1

Mackintosh, S. C., \& Leather, P. (2016). The disabled facilities grant: Before and after the introduction of the better care fund. Derbyshire, UK: Foundations.

Miller, N. A., Kirk, A., Kaiser, M. J., \& Glos, L. (2014). Disparities in access to health care among middle-aged and older adults with disabilities. Journal of Aging \& Social Policy, 26 (4), 324-346. doi:10.1080/08959420.2014.939851

Pettersson, C., Löfqvist, C., \& Malmgren Fänge, A. (2012). Clients' experiences of housing adaptations: A longitudinal mixed-methods study. Disability and Rehabilitation, 34(20), 1706-1715. doi:10.3109/09638288.2012.660596

Sanford, J. A. (2012). Universal design as a rehabilitation strategy: Design for the ages. New York, NY: Springer Publishing Company.

Scottish Executive. (2007). All our futures: Planning for a Scotland with an ageing population. Edinburgh, UK: Author.

Scottish Government. (2009). National standard eligibility criteria and waiting time Guidance. Edinburgh, UK: Author.

Scottish Government. (2012). Age, home and community: A strategy for housing for Scotland's older people: 2012 - 2021. Edinburgh, UK: Scottish Government.

Siegel, P. S., \& Ellis, N. R. (1985). Note on the recruitment of subjects for mental retardation research. American Journal of Mental Deficiency, 89, 433-436.

Szanton, S. L., Wolff, J. W., Leff, B., Thorpe, R. J., Tanner, E. K., Boyd, C., ... Gitlin, L. N. (2014). CAPABLE trial: A randomized controlled trial of nurse, occupational therapist and handyman to reduce disability among older adults: Rationale and design. Contemporary Clinical Trials, 38(1), 102-112. doi:10.1016/j.cct.2014.03.005

Tanner, B., Tilse, C., \& De Jonge, D. (2008). Restoring and sustaining home: The impact of home modifications on the meaning of home for older people. Journal of Housing for the Elderly, 22(3), 195-215. doi:10.1080/02763890802232048

Trench, A., \& Jeffery, C. (2007). Older people and public policy - The impact of devolution. London, UK: Age Concern England.

Watson, S., \& Crowther, L. (2005). Was it worth it? A study into the effectiveness of major adaptations. Nottingham: Nottingham City Council.

Welsh Government. (2013). The strategy for older people in wales 2013-2013 - Living longer, aging well. Cardiff, UK: Author.

Westlin, E., \& Björklund, A. (2016). A Delphi study of occurring information in housing adaptation certificates. Scandinavian Journal of Occupational Therapy, 23(5), 357-365. doi:10.1080/11038128.2016.1177591

Zhou, W., Oyegoke, A. S., \& Sun, M. (2019a). Service planning and delivery outcomes of home adaptations for ageing in the UK. Journal of Housing and the Built Environment, 34 (2), 365-383. doi:10.1007/s10901-017-9580-3

Zhou, W., Oyegoke, A. S., \& Sun, M. (2019b). Cause of delays during housing adaptation for healthy aging in the UK. International Journal of Environmental Research and Public Health, 16(2), 192. doi:10.3390/ijerph16020192 